\title{
Clinicians' Attitudes and Practices on Technology-Supported Notetaking: A Survey
}

\author{
Effie Lai-Chong Law \\ University of Leicester \\ LE1 7RH Leicester \\ United Kingdom \\ Ic19@leicester.ac.uk
}

\author{
Annegret Hagenberg \\ University of Leicester \\ LE1 7RH Leicester \\ United Kingdom \\ ah413@leicester.ac.uk
}

\begin{abstract}
In this paper we report the results of a web-based survey that was aimed at improving our understanding of therapists' attitudes towards - and adoption of - technologies designed to support medical documentation. 310 valid responses from 28 countries were analysed. The PATCH scale was used to measure attitudes towards computers in healthcare. Significant differences in PATCH scores across the included countries were identified. $36 \%$ of the respondents used only paper for notetaking whereas $52 \%$ used both paper- and software-based approaches. Negative and positive experiences of employing the software tools were analysed together with the respondents' suggestions for enhancing those tools. Overall, clinicians' attitudes towards technology-supported notetaking were encouraging, although a number of technical issues remain to be solved.
\end{abstract}

Notetaking. Paper. Affordances. Clinician. Mirror therapy. P.A.T.C.H.

\section{INTRODUCTION}

In recent years, we have witnessed a huge investment of resources in digitalizing healthcare, thanks to the assumption that computing technologies can support clinicians in providing high-quality patient care. Specifically, the design, development and deployment of integrated Electronic Health Record (EHR) systems have all attracted much research interest (Fitzpatrick \& Ellingsen, 2013). One intriguing observation is that to many practitioners paper remains a preferable medium for medical records. This can be attributed to the familiarity and affordances of paper (Sellen \& Harper, 2003; Flanagan et al., 2014). While benefiting from both the potential efficiency and effectiveness provided by computing devices, clinicians tend to adopt a mixed-media approach to documenting patient information (Dudek et al., 2015). It therefore seems that for now paperless clinics or hospitals remain only a distant possibility.

Given this persistent and pervasive reliance on paper-mediated workflow, a variety of technological tools enabling clinicians to work seamlessly with both digital and paper documentation have been developed. However, the results of usability studies on such devices remain inconclusive (e.g. Houben et al. 2015). Indeed, how to enhance the usability and user experience of healthcare technologies is an ongoing challenge for a number of HumanComputer Interaction $(\mathrm{HCl})$ researchers, who collaborate closely with clinicians.
To tackle the bespoke challenge, it is imperative to further explore whether, why and which clinicians have used technological tools to manage medical records. Attempts have been made to collect such data, focusing more on physicians (e.g., Barrett et al, 2003; Dudek et al., 2015; Zandieh et al. 2008) than on therapists (e.g., Saleh et al., 2002; Wiarda et al., 2014). Hence, we have been motivated to conduct a survey to bridge this knowledge gap.

This study was further prompted by the second author's main therapy research interest, viz. the subject of mirror therapy (MT) (Hagenberg \& Carpenter, 2014). This burgeoning subject involves therapeutic intervention for the treatment of onesided pain and functional problems (Ramachandran \& Altschuler, 2009).

In a nutshell, MT or mirror visual feedback is the use of a mirror (previously a mirror box) to create a visual illusion. The mirror is placed between the limbs so that the patient can see the reflection of the sound limb instead of the own impaired, disfigured or nonexisting limb, whilst the impaired limb is not in view.

For this intervention, the plethora of promising but heterogeneous studies limits comparison of data, a problem with which most systematic reviews in MT concur (Ezendam et al., 2009; Rothgangel et al., 2009; Najiha et al., 2015; Thieme et al., 2016). Without comparable medical records, it is impossible to draw conclusions about the impact of MT. To address this issue, an initial and significant 
step is to analyse the approaches undertaken by different clinicians in different countries for recording treatments of those medical conditions where MT is applicable.

However, MT is just one example of how urgently we need standardised notetaking in the health sector.

The aforementioned goals of both research areas, namely $\mathrm{HCl}$ and $\mathrm{MT}$, have driven us to develop a web-based survey to gain insights into: (a) therapists' attitudes and their adoption of technologies to support medical documentation; (b) practice-related issues regarding MT. Considering this paper's length limit and its relevance to different research communities, here we report only on (a), which is more relevant to the $\mathrm{HCl}$ community whereas (b) is more related to the community of rehabilitation research.

Furthermore, in accordance with the basic principles of questionnaire design (Oppenheim, 2000), a survey should not be too long lest it should demotivate respondents. We decided to focus on notetaking, which is a crucial practice of recording information for future references over long-term treatment and patient care (Mueller \& Oppenheimer, 2016). While notetaking can build and maintain trust between clinicians and patients by demonstrating professionalism, paradoxically it may compromise rapport (e.g. reducing eye contact). Whether the use of technologies can mitigate or even aggravate this problem is worth to be further explored.

Overall, we aimed within this survey to answer with empirical data the following research questions:

- How are clinicians' attitudes towards healthcare technologies associated with their adoption of technological tools for notetaking?

- Is there any significant difference in attitudes towards healthcare technologies between clinicians practising in different countries?

- Which types of technological tools are used by clinicians to support notetaking? What positive and negative user experiences have they had? What features would respondents recommend to enhance these tools?

\section{RELATED WORK}

Health information systems (HIS) refer to any system that captures, stores, manages or transmits information related to the health of individuals or the activities of organisations that work within the health sector ${ }^{1}$. The volume of literature on HIS is vast; and several systematic literature reviews (SLRs) on HIS have been published (e.g. Baumgart, 2005; Buntin et al. 2011; Chaudhry et al. 2006; Cresswell \&
Sheikh, 2013; Jones et al. 2014). Results regarding clinicians' attitudes, adoption, and perceived benefits of deploying computing technologies in their practices remain inconclusive. This paper, however, does not aim to verify the findings of the existing SLRs, given that our scope is much more focused, namely, technology-supported notetaking.

Research on notetaking can be dated back to almost a century ago (Crawford, 1925). Not until recently has it primarily been studied in the field of educational psychology (Kiewra, 1989; Kobayashi, 2005). Making notes that lead to desirable outcomes, be they related to formal learning, informal collegial discussion or (the most important goal) good patient care is not easy. Despite its seemingly casual nature, notetaking is a cognitively demanding process. It entails understanding the source material (e.g., a book chapter or a patient's history), deciding on the relative importance of its parts, then rephrasing and rewriting them in a (much) shortened form. These challenges become more acute when notetaking needs to be completed under high time pressure in a distracting setting (e.g. in an emergency room of a hospital) and where there is little margin for errors that could lead to disastrous consequences.

To mitigate the risk of error making and cognitive overload of notetakers, computing technologies have been introduced to notetaking with the intention of improving the accuracy as well as efficiency of the process. Considering the hitherto inconsistent findings (e.g. Stacy \& Cain, 2015), whether and to what extent this goal has been achieved is yet to be fully determined.

Mueller and Oppenheimer (2016) conducted an interesting review of the role of technology in notetaking in four different contexts: classroom, boardroom, hospital room, and courtroom. A significant implication the authors inferred from their review is that designers and developers of technological tools for notetaking should not only aim to alleviate the challenges facing a notetaker (e.g., missing critical information when treating a patient) but also to avoid undermining the process on which the success of the treatment is relied (e.g. building and maintaining trust between the notetaker and the patient).

In what ways are the technology-supported approaches to notetaking more beneficial than the traditional paper-and-pencil one, which has been considered more natural, efficient, easy and effective? Zandieh et al. (2008) conducted interviews with managers and medical directors from paper- or EHR-based practices for their perceptions of the benefits and challenges in implementing an ambulatory EHR. Interestingly,

\footnotetext{
${ }^{1}$ http://phinnetwork.org/resources/health-information-systemshis/
} 
many of their findings are similar to ours in terms of positive and negative user experiences (Section 4.6). For instance, in describing the perceived advantages of EHR, one of their participants remarked that "improved ability to read other people's notes is a definite plus... legibility is crucial in coordinated patient care"; this corroborated another participant's comment that "sometimes it takes great imagination to figure out someone else's handwriting." (ibid, p.757).

From the theoretical point of view, clinicians' prevalent preference for paper can be explained with Gibson's theory of affordances, as posited by Sellen and Harper (2003). Gibson (1977) defined affordances as all action possibilities latent in an object/environment; whether such possibilities are realised is dependent on an agent's capabilities. The differential preferences of the two media (paper vs. digital) can be explicated by the arguments: "The physical properties of paper ... afford many different human actions, such as ... manipulating ... and in combination with a marking tool, writing on." (Sellen \& Harper, 2003, p. 17). In contrast, technological tools have different affordances from paper:"... because it dynamically displays information, it affords the viewing of moving images ... and affords the creation of regular, geometrical, uniform marks ... or text" (ibid, p. 18).

In a more recent research study comparing paperand software-based participatory design (PD, an area where paper-based approaches still prevail), Heintz and colleagues (2015a) identified that the paper-based approach could result in a higher number of ideas elicited with PD whereas the software-based approach could lead to ideas of higher quality.

Above all, based on our empirical data, we could provide further insights into the above queries whether paper-based notetaking approaches remain preferable when compared with their technology-supported counterparts and what the underlying reasons for this may be.

\section{METHODOLOGY}

In the following we first present the design of the survey and then our recruitment strategy.

\subsection{Survey design}

The survey was informed by the second author's research questions regarding MT practice. It was implemented with an open source tool called Limesurvey. The survey consists of five sections, each of which is described in the following.

\subsubsection{Section I: Background data}

Apart from three typical data - age, gender, country of residence - six practice-related questions are shown in Table 1.

Table 1: Questions on demographic data

\begin{tabular}{|l|l|}
\hline Question & Options \\
\hline $\begin{array}{l}\text { Training } \\
\text { discipline }\end{array}$ & $\begin{array}{l}\text { physiotherapy, occupational therapy, } \\
\text { medicine, nursing, psychology, other }\end{array}$ \\
\hline Role & $\begin{array}{l}\text { student, practitioner, teaching staff, } \\
\text { researcher, assistant, other }\end{array}$ \\
\hline $\begin{array}{l}\text { Typical } \\
\text { practice venue }\end{array}$ & $\begin{array}{l}\text { hospital, rehab setting, practice } \\
\text { studio, community centre, home } \\
\text { visits, care home, other }\end{array}$ \\
\hline Practising MT & yes, no \\
\hline
\end{tabular}

3.1.2. Section II: General experiences with computing technologies

We employed the scale abbreviated to P.A.T.C.H. (Pretest for Attitudes Towards Computers in Healthcare; hence PATCH), a standardized tool with established psychometric properties (Atay et al., 2014; Adams, 2015). PATCH was developed by June Kaminski in 1996 and has been revised since then. The version incorporated in our questionnaire was Version 3 released in 2011. It has 50 statements, each of which is rated with a 5-point Likert scale (1: agree strongly; 5 : disagree strongly). Two sub-scores - one for 25 positively worded statements and the other for 25 negatively worded ones - are computed, based on simple formulae, and combined to give a total score ranging from 0 to 100 . The possible score interpretations range from cyberphobia $(0-17)$ through having a realistic view of current computer capabilities in healthcare (53-69) to holding an idealistic view related to computer uses in healthcare (87-100).

While the original target group of PATCH was nurses, we considered the statements applicable to other clinicians. In fact, in searching for relevant instruments, we identified only a limited number of scales. A research study aimed to develop a scale for measuring physicians' attitudes towards computer technology was conducted almost 20 years ago (Cork et al. 1998, who also presented their reviews on the related work in the 60s-90s). Unlike PATCH, that scale for physicians was not updated to include current technologies such as social media, e-health and mobile computing.

\subsubsection{Section III: Notetaking practice}

This section contains six main questions, some of which are conditionally branched to sub-questions. Due to the limited space, only the core phrases used in the questions are displayed in Table 2.

A brief description of SOAP notes is nonetheless needed. SOAP (Subjective, Objective, Assessment, Plan) notes are a structured format for documenting the progress of a patient during treatment. The notes are entered by healthcare professionals into medical records (paper/digital) to support communication with other care providers and to inform the clinical 
reasoning process. The creation of SOAP notes was aimed to address the issue that documentation, despite being a critical aspect of patient care, tends to be neglected or done vaguely (Quinn \& Gordon, 2003). The SOAP format encourages or even obliges the writer to be much more definite and decisive in his or her written summaries.

Table 2: Questions on notetaking practices.

\begin{tabular}{|l|l|}
\hline Question & Option/Format \\
\hline Know SOAP note? & Yes, No \\
\hline Use SOAP note? & Yes, No \\
\hline Notetaking practice? & $\begin{array}{l}\text { - Paper-based only } \\
\text { - Software- } \\
\text { supported only } \\
\text { Both of them }\end{array}$ \\
\hline $\begin{array}{l}\text { Aspects of practice covered in } \\
\text { notetaking? }\end{array}$ & Free text \\
\hline $\begin{array}{l}\text { Paper-based only: Change to } \\
\text { software-supported? } \\
\text { If "Yes", name software tools } \\
\text { If "No", why? } \\
\text { If "Not sure", why? }\end{array}$ & Yes, No, Not sure \\
\hline $\begin{array}{l}\text { Software-supported only/Both: } \\
\text { Name up to 5 software tools } \\
\text { Positive experience } \\
\text { Negative experience } \\
\text { Wish list of missing features }\end{array}$ & $\begin{array}{l}\text { Free text } \\
\text { Free text }\end{array}$ \\
\hline
\end{tabular}

In addition, participants were asked to classify their own level of expertise (i.e. novice, advanced beginner, competent user, proficient user) in ten types of software applications (Table 5).

\subsubsection{Section IV: Outcome measures}

This contains four questions on standardized outcome measures: whether (yes/no), which (up to 5 typical ones), how (paper-based/ computer-based/ both) and when (after how many sessions/weeks/months, or on discharge). Note, however, that the results of this specific section are not reported in this paper.

\subsubsection{Section V: Additional comments}

Two questions: one invites comments on the survey and the other offers the opportunity of being sent a copy of the survey report via email.

\subsection{Participants}

Ethical approval for the launch of the survey was granted by the Research Ethics Committee of the University of Leicester. Recruitment was conducted by the second author with a snowball sampling strategy. First, existing international MT research and clinical contacts were approached. Then, the strategy was expanded to approach 44 gatekeepers, who were members of 22 national physiotherapy organisations, 3 national occupational therapy organisations, 3 national pain organisations, 2 international and 1 European associations on hand therapy. The survey was run from November 2015 to December 2016. This rather long duration was caused by our dependence on the gatekeepers in different countries. Some were responsive but inevitably some were not, thereby taking us some time to prompt and remind the backsliders, and eventually re-negotiate the recruitment strategy.

Note that the dissemination approach varied with individual gatekeepers with some of them posting the URL to the survey on the website of the organisation and some posting the link embedded in a message to mailing lists or social media (e.g. Twitter). The strategy implemented was based on individual organisation's communication protocol. The use of such non-uniform pull and push recruitment strategies made it impractical for us to estimate the corresponding response rates.

\section{RESULTS}

\subsection{Profiles of participants}

The total number of people who viewed the questionnaire was 622, but 192 quit after responding to the first few questions. The number of respondents who completed at least Section 1 (Demographic data) was 430, representing 28 countries as shown in Figure 1 below. The highest number of respondents per country was 57 (Bosnia and Herzegovina, BA), followed by 52 (Russia, RU), 47 (Nigeria, NG), 44 (UK) and 36 (identical for Germany, DE and France, FR).

As data for the variables of interest were captured with items from Section II to IV, we discarded those responses with only demographic data, leaving 310 for further partial or full analysis. The five countries with the highest frequencies remained the same for the whole dataset, though the order was slightly different with Germany sharing a tie with the Netherlands instead of France.

A similar distribution of countries for the 241 full responses (all five sections) was observed with the leading one being the UK $(n=36)$. For subsequent comparisons, only those countries with 10 or more responses were included; this cutoff point coincidentally corresponded to the top ten countries. 


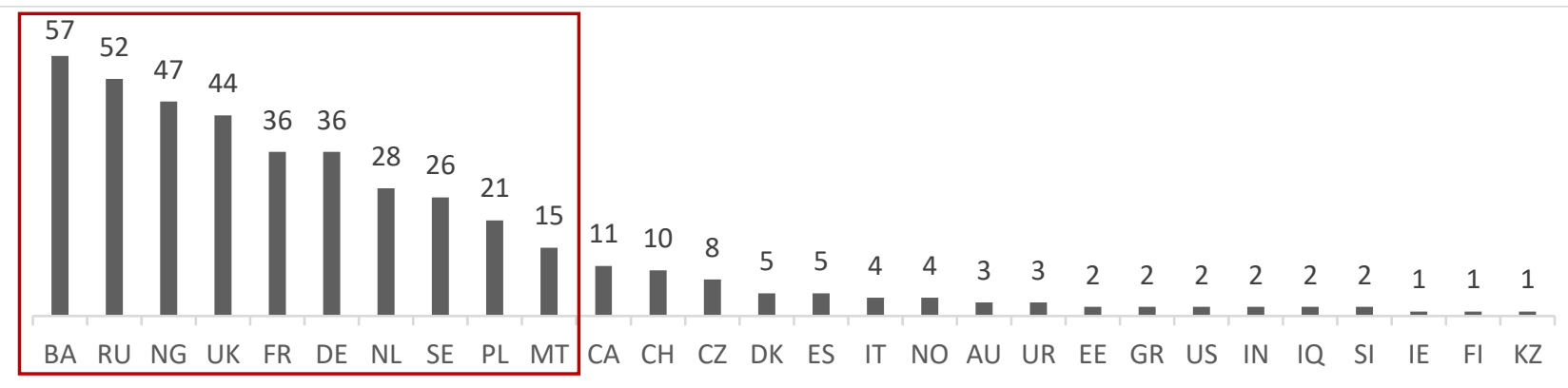

Figure 1: Distribution of respondents $(N=430)$ who completed at least Section 1

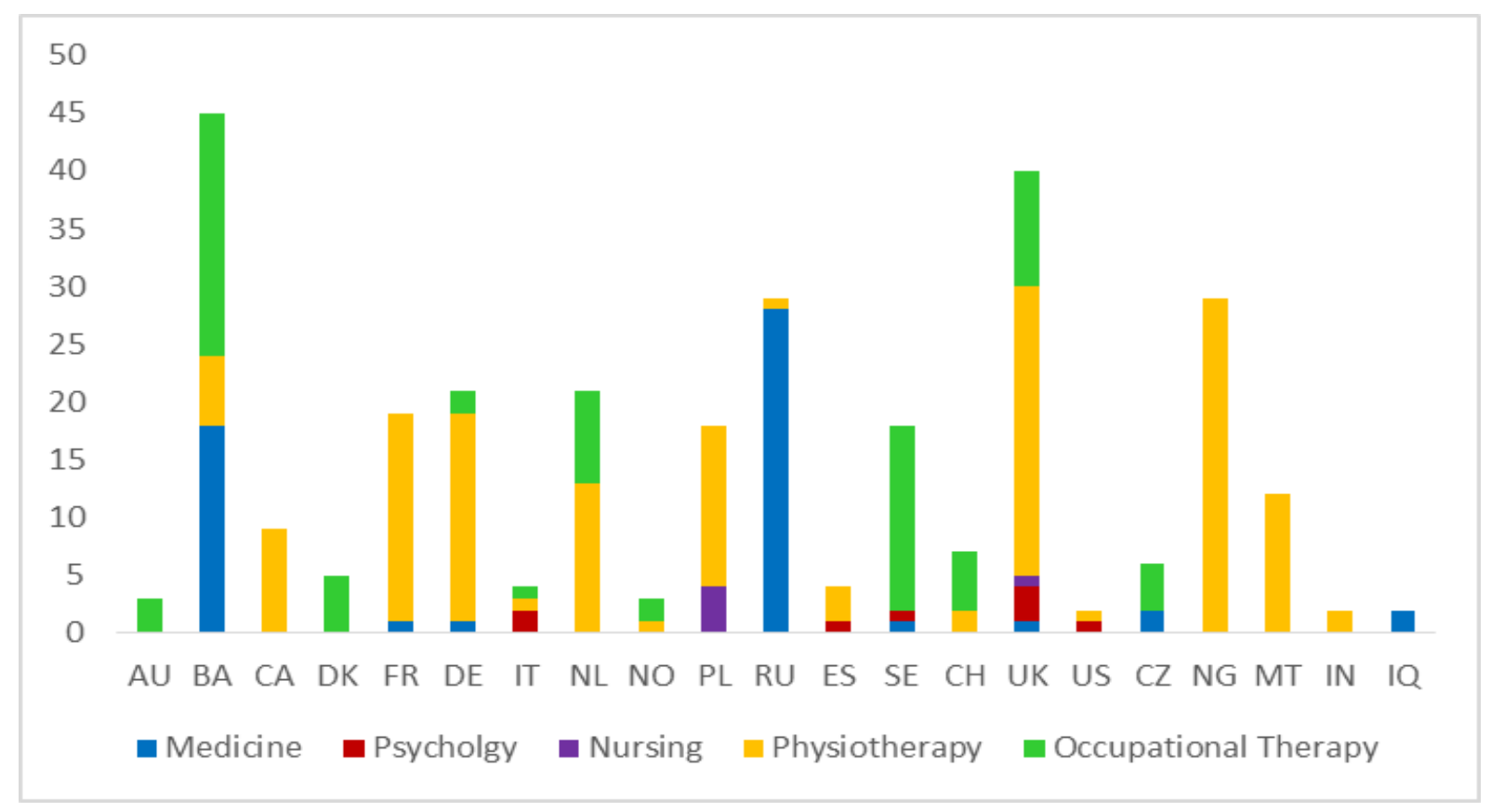

Figure 2. Distribution of professions per country

Table 3: Ten countries with highest number of responses

\begin{tabular}{|l|c|c|c|c|c|c|c|c|c|c|}
\hline & BA & UK & RU & NG & DE & NL & FR & PL & SE & MT \\
\hline Partial & 45 & 41 & 31 & 29 & 21 & 21 & 19 & 18 & 18 & 12 \\
\hline Full & 32 & 36 & 20 & 21 & 16 & 19 & 12 & 18 & 12 & 10 \\
\hline
\end{tabular}

When breaking down the number of responses $(\mathrm{N}=$ $310)$ by training discipline, half of the respondents. $51 \%(n=157)$ were trained in physiotherapy, $25 \%$ $(n=79)$ in occupational therapy, $18 \%(n=57)$ in medicine, $3 \%(n=8)$ in psychology, $2 \%(n=5)$ in nursing and $1 \%(n=4)$ in others. The distribution of training disciplines per country is illustrated in Figure 2 ; UK is the only country with all five types. About $45 \%$ of the respondents $(n=139)$ reported that they had practised MT.

\subsection{Attitudes towards healthcare technology}

The mean PATCH scores $(\mathrm{N}=310)$ was 71.27 (SD $=7.65)$, indicating that on average the respondents were holding an enthusiastic view of the potential of computer use in healthcare. A reliability analysis was carried out on the PATCH scale comprising 50 items. All items correlated satisfactorily (above $r=$ .3) with at least one other item and did not show any signs of redundancy (no correlations stronger than .9). Cronbach's alpha showed the questionnaire to reach acceptable reliability, $\alpha=0.808$.

Results of an ANOVA test indicated that there were highly significant differences in PATCH scores (Section 3.1.2) among the ten countries with the highest number of responses $\left(F_{(9,243)}=3.93, p<.001\right.$, $\left.\eta_{p}^{2}=.127\right)$. Post-hoc Bonferroni tests showed that there were highly statistically significant differences in PATCH scores between the following pairs of countries (Table 4):

Table 4: Significant pairwise comparisons in PATCH

\begin{tabular}{|l|c|c|c|c|}
\hline Countries & $\begin{array}{l}\text { Mean } \\
\text { diff. }\end{array}$ & $\begin{array}{c}\boldsymbol{t}(\mathbf{d f}) \\
(\boldsymbol{p}<\text {.01) }\end{array}$ & $\begin{array}{c}\text { Cohen's } \\
\mathbf{d}\end{array}$ & $\begin{array}{c}\text { Effect } \\
\text { size }\end{array}$ \\
\hline BA vs. UK & 6.64 & $t(84)=3.82$ & 0.82 & 0.38 \\
\hline BA vs. NG & 5.63 & $t(71)=3.3$ & 0.8 & 0.37 \\
\hline PL vs. UK & 3.20 & $t(57)=3.2$ & 0.96 & 0.43 \\
\hline PL vs. NG & 6.31 & $t(44)=3.22$ & 0.97 & 0.44 \\
\hline
\end{tabular}

Interestingly, there were also significant differences in PATCH scores between those who reported they had practised MT $(N=139, M=72.39, S D=7.27)$ and those who reported they had not $(N=169, M=$ 70.36, $S D=7.85)$, with MT practitioners showing 
higher scores $\left(t_{(306)}=2.34, p=.02\right)$. On the other hand, there were no significant differences in PATCH scores between respondents with different training disciplines $\left(F_{(5,302)}=1.48, p>.05\right)$; neither was any there significant differences between the two genders $\left(t_{(306)}=0.14, p>\right.$.05) .

In addition, there were highly positive significant correlations $(p<.01, N=310)$ between PATCH scores and self-rated expertise in seven of the ten software applications (Table 5), ranging from $r=0.27$ (PDA, smartphone) to $r=0.46$ (Email). To a lesser extent, presentation software was significantly correlated with PATCH scores $(r=0.12, p<.05)$; given the nature of clinicians' tasks, this result is reasonable.

Of particular interest was the difference between the two healthcare specific items. Whereas PATCH scores were highly significantly correlated with selfrated expertise in "Hospital Information Systems (HIS) or Electronic Health Record (EHR)" ( $r=0.2$, $p<.01)$, the correlation between PATCH scores and self-rated expertise in medical software packages (e.g. eNoteFile) was insignificant ( $r=0.11, p>.05)$. This can be reflected by the contrasts in the number of respondents classifying themselves as novice versus proficient user (the last two rows in Table 5).

Table 5: Self-rated expertise in ten software applications

\begin{tabular}{|l|c|c|c|c|}
\hline & Novice & $\begin{array}{c}\text { Advanced } \\
\text { Beginner }\end{array}$ & $\begin{array}{c}\text { Competent } \\
\text { user }\end{array}$ & $\begin{array}{c}\text { Proficient } \\
\text { user }\end{array}$ \\
\hline $\begin{array}{l}\text { Word } \\
\text { Processing }\end{array}$ & 7 & 33 & 176 & 94 \\
\hline $\begin{array}{l}\text { Spread- } \\
\text { sheet }\end{array}$ & 27 & 121 & 129 & 33 \\
\hline Database & 84 & 116 & 98 & 11 \\
\hline $\begin{array}{l}\text { Presentation } \\
\text { software }\end{array}$ & 14 & 47 & 160 & 88 \\
\hline $\begin{array}{l}\text { Social } \\
\text { media apps }\end{array}$ & 32 & 57 & 129 & 92 \\
\hline $\begin{array}{l}\text { Search } \\
\text { engines }\end{array}$ & 7 & 21 & 151 & 131 \\
\hline Email & 9 & 15 & 137 & 148 \\
\hline $\begin{array}{l}\text { PDA, } \\
\text { Smartphone }\end{array}$ & 59 & 53 & 120 & 76 \\
\hline $\begin{array}{l}\text { Medical } \\
\text { software } \\
\text { packages }\end{array}$ & 122 & 85 & 79 & 24 \\
\hline HIS or ERS & 87 & 82 & 100 & 41 \\
\hline
\end{tabular}

\subsection{Awareness of SOAP notes}

Respondents were asked to indicate if they were aware of SOAP notes and if so, whether they had used it in their practice. To analyse whether this could be a country-dependent variable, we performed Chi-square tests with the ten countries with the highest response rates. Results showed that there were significant associations between awareness of the SOAP notes and country $\left(X^{2}(9)=\right.$ 102.71; Cramér's phi $=0.71)$. Table 6 shows that four of the 10 countries - Netherlands (NL), UK, Nigeria (NG) and Malta (MT) - had a very high level of awareness as compared with the mean awareness of $52 \%$ (SD $=38 \%$ ) over these ten countries. There was also a highly positive significant correlation between the self-reported awareness and usage of the SOAP note $(r=0.81, p$ $<.001)$.

Table 6: Awareness of SOAP notes per country

\begin{tabular}{|c|c|c|c|}
\hline Country & Aware (\%) & Country & Aware (\%) \\
\hline SE & 8 & PL & 44 \\
\hline DE & 10 & NL & 83 \\
\hline BA & 17 & UK & 91 \\
\hline FR & 29 & NG & 100 \\
\hline RU & 39 & MT & 100 \\
\hline
\end{tabular}

As SOAP notes are captured in a narrative format, a SOAP-oriented technological tool can address the issue of legibility and enhance accuracy and efficiency of recording, provided the notetaker is proficient at typing.

\subsection{Notetaking media}

With regard to notetaking media, respondents were asked to indicate if they used paper only, software only, or both.

Table 7: Use pattern of the notetaking media per country

\begin{tabular}{|l|c|c|c|c|c|c|c|c|c|c|}
\hline & BA & FR & DE & NL & PL & RU & SE & UK & NG & MT \\
\hline $\boldsymbol{P a}$ & 9 & 6 & 11 & 0 & 15 & 2 & 3 & 14 & 20 & 6 \\
\hline Sw & 3 & 0 & 0 & 9 & 0 & 1 & 3 & 4 & 0 & 1 \\
\hline Bt & 26 & 11 & 9 & 12 & 3 & 21 & 9 & 20 & 4 & 4 \\
\hline
\end{tabular}

$\mathrm{Pa}=$ Paper-based only; Sw = Software-supported only; $B t=$ Both

Results of Chi-square tests indicated there were significant differences in the use of notetaking media among the ten countries $\left(X^{2}(18, N=226)=96.5, p=\right.$ .001) (Table 7). No respondents from the Netherlands (NL) used paper only whereas no respondents from France (FR), Germany (DE), Poland (PL) and Nigeria (NG) used software only. $P L$ and NG showed a high percentage, 83\%, for paper-based only.

Table 8: PATCH scores of the notetaking media groups

\begin{tabular}{|l|c|c|l|}
\hline \multirow{2}{*}{ Notetaking Medium } & \multicolumn{2}{|c|}{ PATCH scores } & \multirow{2}{*}{ N } \\
\cline { 2 - 3 } & Mean & SD & \\
\hline Paper-based only & 71.51 & 8.19 & 100 \\
\hline Software-based only & 74.33 & 8.01 & 33 \\
\hline Both & 70.75 & 7.43 & 144 \\
\hline Overall & 71.45 & 7.83 & 277 \\
\hline
\end{tabular}

No significant differences in PATCH scores among the three groups were detected $\left(F_{(2,274)}=2.85, p=\right.$ $.06)$. Expectedly, the scores of the 'software-based only' respondents were highest among the groups (Table 8).

\subsection{Intention to adopt software-based approach}

Fifty out of 100 respondents using the paper-based only approach to notetaking indicated that they intended to change to the software-based approach. The rationales provided were that using notetaking software tools could: 
- avoid duplicated data;

- document client history;

- monitor quality of services

- provide safe storage;

- visualize results;

However, seven of them reported that they did not know any of such a tool whereas two stated that they would use any tools provided.

In addition, the expected quality of such software tools was stated, including; ease of use (especially for data retrieval and search), usefulness, familiarity (i.e. branded products, adaptations of existing software applications), affordability, and durability.

Several functional requirements for notetaking software tools were derived from respondents' comments:

- software dedicated to assessment and patient review as well as outcome measures;

- open-source software with advanced features and actively developed by domain experts;

- spreadsheets with tabular forms differentiating between assessment and treatment;

- supporting the SOAP notes format (cf. Section 4.3)

- suitable for small and mobile hardware;

On the other hand, 18 of the respondents using a 'paper-based-only' approach to notetaking indicated that they had no intention of changing to the software-based approach, whereas 31 indicated they were not sure about it (Note: one did not respond to this question). The 'no intention' group mentioned several major reasons, including: no access to computer or software; having heard negative comments on existing software tools, which were perceived as complicated; being accustomed to writing on paper, given its flexibility, as remarked by one participant:

"With hand writing, I can easily modify my notes without deleting ... easily link the different information I have about my patients. I think computer is very good for writing articles and research, but not really for taking note with a patient." (P488, medicine, France)

The reasons given by the "not sure" respondents were categorised dichotomously into technical and personal issues.

Technical issues:

- compromising the quality of patient care as it would be difficult to interact with a computer while treating patients;

"I feel that software tools will dehumanise client care and also [it would] be difficult to access all MDT discussions and assessments. I feel paper notes work better to recall a history, are easier to complete during the day. It would be difficult to access computer at the time of assessment and [I] feel that key documentation could be missed." (P10, occupational therapist, UK).
- using software tools could be time-consuming; "I just don't want anything that would further waste my time that is already limited." (P131, physiotherapist, Nigeria)

- paper can better support information retrieval, data entry into a form, and 'wet ink' signature;

"I think it's easier when we are with the patient to write on paper than to write on a computer" (P234, physiotherapist, France)

"We had been given laptops loaded with software in the past to record patient contact notes. However, the notes required patient and clinician signatures with a pen which was difficult to use on the laptop. The trial did not proceed very far." (P12, occupational therapist, UK)

- insufficient infrastructural support, including limited access to computers, unstable internet connection, lack of appropriate software;

"Very limited access to computers so this would be impractical." (P322, physiotherapist, Canada)

- the unknown quality of software tools, especially their usability and reliability;

"would like to know how user friendly the system is and would really want auto populate as an option. I am a slow typer so I would like it to be as efficient as possible. "(P345, physiotherapist, Canada).

"it depends on a quality of a software, data included and necessary data to include; the necessity to log in and off. The amount of data to use, the possibilities of that software." (P459, physiotherapist, Poland).

Personal issues:

- low self-confidence in deploying technology; "I might not be able to use the software appropriately" (P273, physiotherapist, Nigeria)

- preference for personal hardware and personalised software;

"would depend on how reliable the system was and how it's used. Would want to be able to have my own assessment forms on there, not ones written for me without consultation. Would also depend on how accessible it was. Would need to do it as go along in each treatment session to avoid duplication." (P439, physiotherapist, UK)

- being more confident and comfortable with paper;

"Hand written is comfortable on first contact with patient. I can later update in a software-supported approach." (P194, physiotherapist, US)

\subsection{User experience \& improvement suggestions}

Respondents were asked to name up to 5 software tools that they had used to support notetaking in their clinical practice. While 177 respondents indicated that they used software only or both paper and software for notetaking (Table 8), only 111 responded to this question; almost half of them named just one tool (Table 9). 
Table 9: Number of software tools to support notetaking

\begin{tabular}{|l|c|c|c|c|c|}
\hline $\begin{array}{l}\text { Number of software tools } \\
\text { used for notetaking }\end{array}$ & 5 & 4 & 3 & 2 & 1 \\
\hline Number of respondents & 6 & 13 & 19 & 22 & 51 \\
\hline
\end{tabular}

We clustered the instances of software tools named, resulting in eight categories (Table 10). The most named application is Word (47 times), followed by Excel (20 times). This is not surprising as these tools are widely adopted in a variety of learning as well as working contexts. Interestingly, only one dedicated notetaking tool, namely, Evernote, was mentioned by three respondents. Apparently, our sample of respondents seemed not aware of more recent ones such as Carenotes, Simplenotes and Notability. It can be inferred that they have been comfortable with their existing and more familiar tools (Section 4.5).

In addition, respondents were asked to describe their experiences - positive as well as negative - in deploying the software tools.

\subsubsection{Positive experiences}

There were altogether 236 responses, which we clustered into 6 categories (Table 11). The one with the highest count is 'non-functional quality', subsuming 17 types of which the four mostly mentioned are: easy (22), fast (19), good (14), simple (11); some quality terms of lower frequency are satisfactory, positive, clear, and visual aesthetics. Clearly, ease of use and efficiency are critically relevant for clinicians who always work under high time pressure.

In terms of functionality, respondents recognised 19 different types of function supported by the tools. The most frequently mentioned functions are: text processing; information storage and retrieval; communication; availability of standards, guidelines and templates; data collection; assessment and analysis; planning; integrity check; digital signature.

Table 10: Categories of the software tools used

\begin{tabular}{|l|c|c|l|}
\hline \multicolumn{1}{|c|}{ Category } & Type & Count & \multicolumn{1}{|c|}{ Examples } \\
\hline $\begin{array}{l}\text { Standard office } \\
\text { applications }\end{array}$ & 16 & 99 & $\begin{array}{l}\text { Excel (20), Word (47), } \\
\text { Pages (4) }\end{array}$ \\
\hline $\begin{array}{l}\text { Cloud-based } \\
\text { technical } \\
\text { solutions }\end{array}$ & 18 & 23 & $\begin{array}{l}\text { Cerner (2), Cosmic } \\
\text { (2), Lorenzo }\end{array}$ \\
\hline $\begin{array}{l}\text { Outcome } \\
\text { measures }\end{array}$ & 15 & 21 & $\begin{array}{l}\text { PACS, Visiocoach, } \\
\text { xCare(2) }\end{array}$ \\
\hline $\begin{array}{l}\text { Premise-based } \\
\text { systems }\end{array}$ & 15 & 17 & $\begin{array}{l}\text { EPIC, TIARA, } \\
\text { PhysioTools (3) }\end{array}$ \\
\hline $\begin{array}{l}\text { Specific } \\
\text { medical } \\
\text { conditions }\end{array}$ & 7 & 14 & $\begin{array}{l}\text { KISS (2), Intramed (4), } \\
\text { Paranice (2) }\end{array}$ \\
\hline $\begin{array}{l}\text { Across health- } \\
\text { care settings } \\
\text { (med opt-in) }\end{array}$ & 2 & 12 & $\begin{array}{l}\text { KIS (10), SystmOne } \\
\text { (2) }\end{array}$ \\
\hline $\begin{array}{l}\text { Dedicated } \\
\text { notetaking app }\end{array}$ & 1 & 3 & Evernote (3) \\
\hline $\begin{array}{l}\text { Patient health } \\
\text { monitor }\end{array}$ & 1 & 1 & medlink \\
\hline
\end{tabular}

Table 11: Aspects of tools for positive experiences

\begin{tabular}{|l|c|}
\hline Category & Count \\
\hline Non-functional quality (17 types) & 127 \\
\hline Functionality (19 types) & 46 \\
\hline $\begin{array}{l}\text { Access to shared, integrated and } \\
\text { interdisciplinary information }\end{array}$ & 41 \\
\hline Usefulness & 5 \\
\hline Legibility & 4 \\
\hline Free & 2 \\
\hline
\end{tabular}

A good number of respondents considered access to multi-source information as positive experience enabled by the tools. For instance, P474 (physiotherapist, France) commented that

\footnotetext{
"Transferable from all therapist's iPad, everyone treating the patients can access updated to the minute info."
}

Only a small number related their experience to the cost of the tools. It could be that most of the tools were provided free of charge in their practice venue.

\subsubsection{Negative experiences}

There were 225 responses on negative experiences in deploying the software tools mentioned. Among them, 58 were 'no' ('nil', 'none', 'nothing', 'don't have') and 5 were too brief to know about the related experience (e.g. 'file system'). The remaining were categorised; those with a frequency of 5 or higher are listed in Table 12. It is intriguing to know that dependency on the Internet and computing technology was regarded as the major negative aspect of using software tools. The other aspects of low frequency ( 1 to 3 ) included: preparation work required, costs, lack of specificity, too simple, errorprone, compromised interpersonal interaction, and safety concern.

Table 12: Negative experiences of using software tools

\begin{tabular}{|l|c|}
\hline Category & Count \\
\hline Dependency (the Internet/technology) & 20 \\
\hline Complicated/too detailed & 18 \\
\hline Limited functionality & 16 \\
\hline Lack of interoperability and integration & 15 \\
\hline Slow & 14 \\
\hline Time-consuming and delay & 11 \\
\hline $\begin{array}{l}\text { Poor system performance (crash, low } \\
\text { searchability) }\end{array}$ & 11 \\
\hline Restrictive templates and forms & 8 \\
\hline Low user friendliness/bad Ul design & 8 \\
\hline $\begin{array}{l}\text { Limited infrastructure (computing devices, } \\
\text { office space) }\end{array}$ & 8 \\
\hline Poor learnability & 6 \\
\hline Lack of flexibility or adaptability & 5 \\
\hline Loss of data & 5 \\
\hline $\begin{array}{l}\text { Negative emotions (uncomfortable, } \\
\text { confused, lost, frustrated) }\end{array}$ & 5 \\
\hline
\end{tabular}


Quotes of some respondents can illustrate the above points:

"Sometimes Dragon does not learn your accent or how you say something and makes the same mistake over and over, similarly if the internet connection is "dodgy" you can't complete your dictation or your notes" (P538, physiotherapist, UK)

"Can't use it with Windows" (P252, OT, Switzerland)

"It's too complex for incidental use" (P352, occupational therapist, Bosnia \& Herzegovina)

"less face to face discussion as we all go back to offices to write notes" (P541, occupational therapist, UK)

"Sometimes the program would not print out A4 size was too small and occasionally hard to find exactly what I wanted - could to with extra stretches /exercise section. System crashing and losing all the work! No auto back up in program! No way to lock appointments and stop rearrangement without your knowledge which can cause" (P188, physiotherapist, Germany)

"Inflexible, badly adaptable, much free text should have been given, no integrated assessments or findings" (P319, physiotherapist, Canada)

\subsubsection{Improvement suggestions}

For the question on desirable functions that might be added to support notetaking, 119 responses were collected. Among them, 36 were 'no' or 'nothing', and nine are irrelevant (e.g. "happy with everything") or too brief to be comprehensible (e.g. "length of note"). The remaining 74 were analysed and coded as follows (in order of frequency):

- Specific functions (19): visualisation (charts, body parts, dynamic data, colour-coded roles), translation, templates, patient survey, note stacking, measurement;

- Usability (11): configurability/customisability (user control and flexibility), user-friendliness minimalistic user interface design, clarity of notation and abbreviation;

- Automatic features (10): backup, language check and correction, pre-fill form, saving, updating, autocue, and session time alert;

- Information (9): drugs, patient history, definition of medical terms, patient exercise regimes, professional community;

- Interaction modality (7): voice input, hand drawing;

- Supporting varied datatypes (7): audio files, videos, pictures, photos;

- Interoperability (5): integration with other tools;

- Infrastructure (4): Internet connectivity;

- Training (2)

Quotes of some respondents can illustrate some the above points:

"being able to configure so only the features I use are present. I would estimate that I don't use $80 \%$ of the features available" (P541, occupational therapist, UK)
The above response resonates with Nielsen's (1994) heuristic on minimalistic design as users could be overwhelmed by excessive features. Furthermore, it is intriguing to know that some respondents have deployed software tools with a more sophisticated interaction modality, namely, voice input:

"Sometimes the surgeon's notes have not been written, the speech recognition program did not function as well as planned so we still have to listen to what they say instead, making it more difficult to go back and check what was said about a certain detail." (P105, occupational therapist, Norway)

Some of the required functions were mutually contradictory. While some asked for more structured templates, some demanded more freedom.

"more place and liberty to write and add tables" (P251, occupational therapist, Switzerland)

\section{DISCUSSION}

Results of the survey showed that there exist a range of attitudes towards and adoption of technological tools for notetaking within and across different countries. The functional and nonfunctional qualities contributing to the positive and negative experiences of the respondents (Section 4.6.1 and Section 4.6.2) were comparable to those of interactive technologies deployed by nonclinicians, for instance, interactive educational technologies for teachers and students (e.g., Heintz et al., 2015b). Nonetheless, in designing applications for clinicians, one critical requirement is that notetakers (clinicians) are only required to interact with the screen at a minimum level, lest it would undermine patient-carer interaction such as eye contact, which is essential for building rapport and trust. The potential of speech recognition as a technical solution to address this issue was already proposed more than a decade ago:

"In the future, authorised, secure logons to the PDA and data entry will be done with combined speech and fingerprint recognition by sophisticated audio hardware and a new high-resolution generation of touch-sensitive screens" (Baumgart, 2005, p.1219).

In fact, Baugmart's vision has already been realised thanks to the advent of voice-controlled user interfaces (e.g. Oka \& Matsushima, 2016). Interestingly, some of our survey's respondents commented on the low reliability and accuracy of such interaction modalities (Section 4.6.2). Clearly, more research needs to be done in this area.

A substantial percentage of clinicians were paperbased only $(36 \%$ of those responded to the related question, Table 8) whereas $52 \%$ used both paper and software tools to support notetaking. This resonates with the observations made by Houben et al (2015), although their participants were medical 
students. They remarked that the heavy reliance on paper to document medical records seems incongruent with the extent to which EHRs are integrated into healthcare systems in general. The explanation can probably be boiled down to the fact that paper makes clinicians more efficient, given its inherent naturalness and other affordances. Houben et al (2015) also referred to Harper et al.'s (1997) framework of paper affordances - flexibility, markability, portability and accessibility, all of which can be adduced in explaining our results.

There are some limitations of our work. First, like all surveys, we relied on respondents' self-reported data; the actual behavioural practices cannot be known or verified. Second, the number of respondents varied substantially across the countries involved, ranging from 1 up to 57 . The differences could be attributed to the varied recruitment strategies employed by the gatekeepers, who might be constrained by certain organisational policies. While one might query the representativeness of the samples, the number of physiotherapists and occupational therapists (our main target groups) within the whole dataset was reasonably high enough to enable us to answer our research questions. Third, strictly speaking, our survey was not a cross-cultural comparison study, because we have not looked systematically into the related cultural factors, for instance, asking how clinicians are trained in their respective countries, or even seeking to trace their habits back to earlier education - whether and how notetaking skills are taught in the classroom, given that it is a good general learning strategy. However, notetaking skills applied at schools are not necessarily applicable to clinical settings.

\section{CONCLUSION}

In this concluding section, we revisit the three research questions posed in the Introduction:

- The clinicians' attitudes towards healthcare technologies were generally positive, as shown by their average high PATCH scores. Their attitudes towards healthcare technologies had no significant relationship with the adoption of technological tools for notetaking.

- There were significant differences in attitudes towards healthcare technologies among the clinicians practising in different countries. This might be attributed to the varied level of access to computing infrastructure.

- A broad range of technological tools were employed by the clinicians to support notetaking. A majority tended to use typical office applications (text processing, spreadsheets) rather than dedicated software. Familiarity with these commonly-used tools bolsters both the clinicians' confidence and their willingness to deploy them.

Overall, clinicians' attitudes towards technologysupported notetaking were encouraging, although a number of technical issues remain to be solved.

\section{ACKNOWLEDGEMENTS}

We would like to express our gratitude to the following organisations for disseminating the survey:

- European Federation of Societies for Hand Therapy (EFSHT)

- Malta Association of Physiotherapists (MAP)

- Deutscher Verband für Physiotherapie e.V. (ZVK), Germany

- Medical Rehabilitation Therapists (Registration) Board of Nigeria

- Institute for the Physical Medicine and Rehabilitation "Dr Miroslav Zotović", Banjaluka, Republic of Srpska / Bosnia and Herzegovina

- Russian Chapter of European Pain Federation EFIC (Russian Association for the Study of Pain)

- Jerzy Kukuczka Academy of Physical Education in Katowice/Poland

Last but the least, our thanks go to $\mathrm{Dr}$ Robin Edwards for reviewing and copy-editing the penultimate version of this paper.

\section{REFERENCES}

Adams, S. L (2015) Nurses Knowledge, Skills, and Attitude Toward Electronic Health Records (EHR). $\mathrm{PhD}$ Thesis for the Degree of Doctor of Nursing Practice. Walden University.

Atay, S., Arikan, D., Yilmaz, F., Aslanturk, N. \& Uzun, A. (2014). Nursing and midwifery students' attitudes to computer use in healthcare. Nursing Practice Today, Quarterly, 1 (3): 147-154.

Barrett, J.R., Strayer, S.M., \& Schubart, J.R. (2004). Assessing medical residents' usage and perceived needs for personal digital assistants. International Journal of Medical Informatics, 73, 25-34.

Baumgart, D. C. (2005). Personal digital assistants in health care: experienced clinicians in the palm of your hand? The Lancet, 366(9492), 1210-1222.

Buntin, M. B., Burke, M. F., Hoaglin, M. C., \& Blumenthal, D. (2011). The benefits of health information technology: a review of the recent literature shows predominantly positive results. Health affairs, 30(3), 464-471.

Chaudhry, B., Wang, J., Wu, S., Maglione, M., Mojica, W., Roth, E., ... \& Shekelle, P. G. (2006). Systematic review: impact of health information technology on quality, efficiency, and costs of medical care. Annals of internal medicine, 144(10), 742-752. 
Cork, R. D., Detmer, W. M., \& Friedman, C. P. (1998). Development and initial validation of an instrument to measure physicians' use of, knowledge about, and attitudes toward computers. Journal of the American medical informatics association, 5(2), 164-176.

Crawford, C. C. (1925). Some experimental studies of the results of college note-taking. The Journal of Educational Research, 12(5), 379-386.

Cresswell, K., \& Sheikh, A. (2013). Organizational issues in the implementation and adoption of health information technology innovations: an interpretative review. International journal of medical informatics, 82(5), e73-e86.

Dudek, N. L., Papp, S., \& Gofton, W. T. (2015). Going paperless? Issues in converting a surgical assessment tool to an electronic version. Teaching and learning in medicine, 27(3), 274-279.

Ezendam, D., Bongers, R. M., \& Jannink, M. J. A. (2009) Systematic review of the effectiveness of mirror therapy in upper extremity function. Disability \& Rehabilitation, 31(26):2135-49.

Fitzpatrick, G., \& Ellingsen, G. (2013). A review of 25 years of CSCW research in healthcare: contributions, challenges and future agendas. Computer Supported Cooperative Work (CSCW), 22(4-6), 609-665.

Flanagan, M. E., Saleem, J. J., Millitello, L. G., Russ, A. L., \& Doebbeling, B. N. (2013). Paper-and computer-based workarounds to electronic health record use at three benchmark institutions. Journal of the American Medical Informatics Association, 20(e1), e59-e66.

Gibson, J.J. (1977). The Theory of Affordances. In R. Shaw \& J. Bransford (eds.). Perceiving, Acting, and Knowing: Toward an Ecological Psychology (pp. 67-82). Hillsdale, NJ: Erlbaum.

Hagenberg, A., \& Carpenter, C. (2014). Mirror visual feedback for phantom pain: international experience on modalities and adverse effects discussed by an expert panel: a Delphi study. PM\&R, 6(8), 708-715.

Harper, R. H., O'Hara, K. P., Sellen, A. J., \& Duthie, D. J. (1997). Toward the paperless hospital? British journal of anaesthesia, 78(6), 762-767.

Heintz, M., Law, E. L. C., \& Soleimani, S. (2015a). Paper or Pixel? Comparing Paper-and Tool-Based Participatory Design Approaches. In Proc. of IFIP TC 13 Conference on Human-Computer Interaction (INTERACT) (pp. 501-517). Springer.

Heintz, M., Law, E. L.-C., Manoli, C., Zacharia, Z., and van Riesen, S. A. (2015b). A survey on the usage of online labs in science education: Challenges and implications. In Proceedings of IEEE Global Engineering Education Conference (EDUCON), IEEE (pp.827-835).

Houben, S., Frost, M., \& Bardram, J. E. (2015). Collaborative affordances of hybrid patient record technologies in medical work. In Proc. of ACM
Conference on Computer Supported Cooperative Work \& Social Computing (pp. 785-797). ACM.

Jones, S. S., Rudin, R. S., Perry, T., \& Shekelle, P. G. (2014). Health information technology: an updated systematic review with a focus on meaningful use. Annals of internal medicine, 160(1), 48-54.

Kiewra, K. A. (1989). A review of note-taking: The encoding-storage paradigm and beyond. Educational Psychology Review, 1(2), 147-172.

Kobayashi, K. (2005). What limits the encoding effect of note-taking? A meta-analytic examination. Contemporary Educational Psychology, 30(2), 242262.

Lau, F., Kuziemsky, C., Price, M., \& Gardner, J. (2010). A review on systematic reviews of health information system studies. Journal of the American Medical Informatics Association, 17(6), 637-645

Mueller, P. A., \& Oppenheimer, D. M. (2016). Technology and note-taking in the classroom, boardroom, hospital room, and courtroom. Trends in Neuroscience and Education, 5(3), 139-145.

Najiha, A., Alagesan, J., Rathod, V. J., \& Paranthaman, P. (2015). Mirror Therapy: A Review of Evidence. International Journal of Physiotherapy and Research, 3(3):1086-90.

Nielsen, J., \& Molich, R. (1990, March). Heuristic evaluation of user interfaces. In Proceedings of the SIGCHI conference on Human factors in computing systems (pp. 249-256). ACM.

Oka, T., \& Matsushima, K. (2016, March). New design of a manipulator control interface that employs voice and multi-touch command. In The Eleventh ACM/IEEE International Conference on Human Robot Interaction (pp. 487-488). IEEE Press.

Oppenheim, A. N. (2000). Questionnaire design, interviewing and attitude measurement. Bloomsbury Publishing.

Quinn, L. \& Gordon, J. (2003). Functional outcomes Documentation for rehabilitation. Saunders (Elsevier Science), St. Louis, Missouri.

Ramachandran, V. S., \& Altschuler, E. L. (2009). The use of visual feedback, in particular mirror visual feedback, in restoring brain function. Brain, 132(7):1693-710.

Rothgangel, A. S., Braun, S. M., Beurskens, A. J., Seitz R. J., \& Wade, D.T. (2011). The clinical aspects of mirror therapy in rehabilitation: a systematic review of the literature. International Journal of Rehabilitation Research, 34(1):1-13.

Saleh K J., Radosevich D.M., Kassim R.A. et al. (2002). Comparison of commonly used orthopaedic outcome measures using palm-top computers and paper surveys. Journal of Orthopaedic Research, 20, 1146-1151.

Sellen, A. J. and Harper, R. H. (2003). The myth of the paperless office. MIT press. 
Stacy, E. M., \& Cain, J. (2015). Note-taking and Handouts in The Digital Age. American journal of pharmaceutical education, 79(7), 107.

Thieme, H., Mehrholz, J., Pohl, M., Behrens, J., \& Dohle, C. (2012). Mirror therapy for improving motor function after stroke. Cochrane Database of Systematic Reviews, 3.

Wiarda, N. R., McMinn, M. R., Peterson, M. A., \& Gregor, J. A. (2014). Use of technology for note taking and therapeutic alliance. Psychotherapy, 51(3), 443. 